\title{
Osseous metaplasia of endometrium: a rare cause of secondary infertility
}

\author{
Nitin H. Shah ${ }^{1}$, Kalyani G. Kale ${ }^{1}$, Vaishali N. Shah ${ }^{2}$ \\ ${ }^{1}$ Department of Obstetrics \& Gynaecology, Vardann Hospital: Centre of Excellence for laparoscopy and IVF, Mumbai, \\ Maharashtra, India \\ ${ }^{2}$ Department of Anesthesiology, Vardann Hospital: Centre of Excellence for laparoscopy and IVF, Mumbai, \\ Maharashtra, India
}

Received: 13 December 2015

Accepted: 07 January 2016

*Correspondence:

Dr. Kalyani G. Kale,

E-mail: kalyanik27m@gmail.com

Copyright: (c) the author(s), publisher and licensee Medip Academy. This is an open-access article distributed under the terms of the Creative Commons Attribution Non-Commercial License, which permits unrestricted non-commercial use, distribution, and reproduction in any medium, provided the original work is properly cited.

\begin{abstract}
Osseous metaplasia of the endometrium is a rare condition with formation of bony tissue inside the uterus, particularly the endometrium. The etiology of this disorder is not completely understood, with various hypotheses being put forward to explain its occurrence. It is an important cause of secondary infertility, although it may present with various other gynecological symptoms. It can be suspected on ultrasonography due to its peculiar appearance and can be completely cured following hysteroscopic resection. Here we present a case of a 30 years old female presenting with hypomenorrhoea and secondary infertility following a first trimester abortion. Ultrasonography showed presence of dense linear echogenic band in the uterus suggestive of calcification. Hysteroscopy revealed multiple bony fragments of varying shapes and sizes $(0.2-2 \mathrm{~cm})$ in the uterine cavity which were removed using a hysteroscopic grasper and the cavity was restored to normal. There were no procedure related complications. Presence of bony tissue was confirmed on histopathology. Patient had a spontaneous conception 3 months after the procedure and delivered a healthy male child at term. Thus, in our case, hysteroscopy was a safe and effective modality for diagnosis as well as treatment of this rare condition. Successful hysteroscopic treatment was followed by a spontaneous conception and a good pregnancy outcome.
\end{abstract}

Keywords: Osseous, Metaplasia, Endometrium, Infertility

\section{INTRODUCTION}

Osseous metaplasia of endometrium is a benign pathological condition with presence of mature or immature bone inside the uterus and endometrium. It is a rare entity with an estimated incidence of $3 / 10,000 .{ }^{1}$ Although rare, it is an evolving and important cause of secondary infertility. ${ }^{2}$ Most of the cases show a temporal association with antecedent spontaneous or induced abortion. ${ }^{3-5}$ Many theories of its occurrence have been postulated, the most accepted one is metaplasia of the endometrial stromal cells, particularly fibroblasts, into bone forming osteoblasts. ${ }^{6}$ Successful hysteroscopic resection of the bony fragments improves conception rates and pregnancy outcomes. $5,7,8$

Here we present one such case of a 30 years old female presenting with secondary infertility and hypomenorrhoea managed hysteroscopically resulting in successful conception. 


\section{CASE REPORT}

A 30 years old female presented to our outpatient department with complaints of hypomenorrhoea since 2 years and secondary infertility. She was married since 10 years, had a full term normal vaginal delivery of a healthy female child 6 years ago followed by a spontaneous abortion at 8 weeks of gestation 2 years back which was treated by dilatation and curettage. Her previous menstrual history was normal. There was no history of galactorrhoea, thyroid disorder, tuberculosis or any chronic medical/surgical illnesses. Her general, systemic and bimanual pelvic examination revealed no significant abnormality.

Husband semen analysis was within normal limits. Her routine haematological investigations (complete haemogram, fasting and post lunch blood sugar, liver and kidney function tests) and hormonal profile were completely normal (Thyroid Stimulating Hormone$2.3 \mu \mathrm{IU} / \mathrm{ml}$, Prolactin- $11 \mathrm{pg} / \mathrm{ml}$, Follicle stimulating hormone- $6.3 \mathrm{mIU} / \mathrm{ml}$, Luteinizing hormone- $4.2 \mathrm{mIU} / \mathrm{ml}$ ). Serum calcium levels were within normal limits. Ultrasonography of pelvis revealed a normal size uterus with dense linear echogenic band in the endometrial cavity causing posterior acoustic shadowing suggestive of calcification (Figure 1). Patient was posted for diagnostic laparoscopy and hysteroscopy. Tubal patency was confirmed by dye testing. Hysteroscopy was performed with saline as a distension medium, using a $4 \mathrm{~mm}$ Hopkins forward oblique $30^{\circ}$ telescope (Karl Storz). Hysteroscopy revealed multiple small bony fragments in the uterine cavity, at the internal os and over the left cornu (Figure 2). Around 10-15 bony fragments of varying shapes and sizes $(0.2-2 \mathrm{~cm})$ were removed using a 5Fr hysteroscopic grasper (Figure 3). Uterine cavity was restored to normal. Post-operative period was uneventful without any complications. Histopathological examination revealed mature bone tissue surrounded by endometrial glands in secretory phase and there was absence of any products of conception, granulomas or inflammatory reaction. TB-PCR examination of the endometrium was negative.

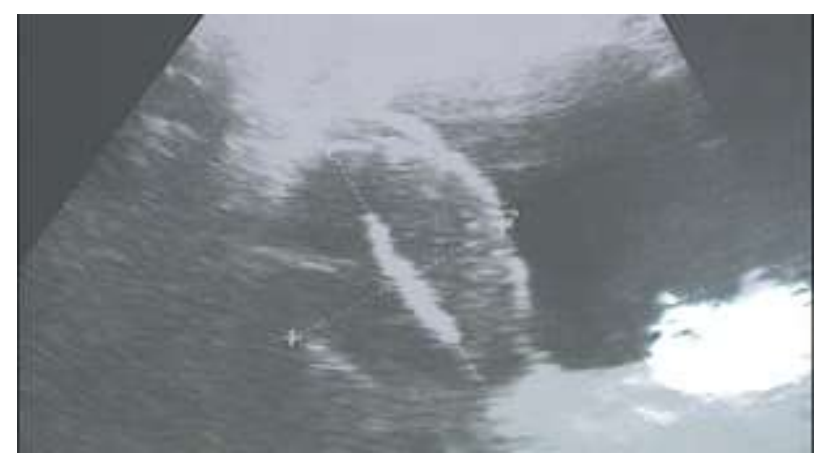

Figure 1: USG showing dense linear echogenic band in the uterus with acoustic shadowing.

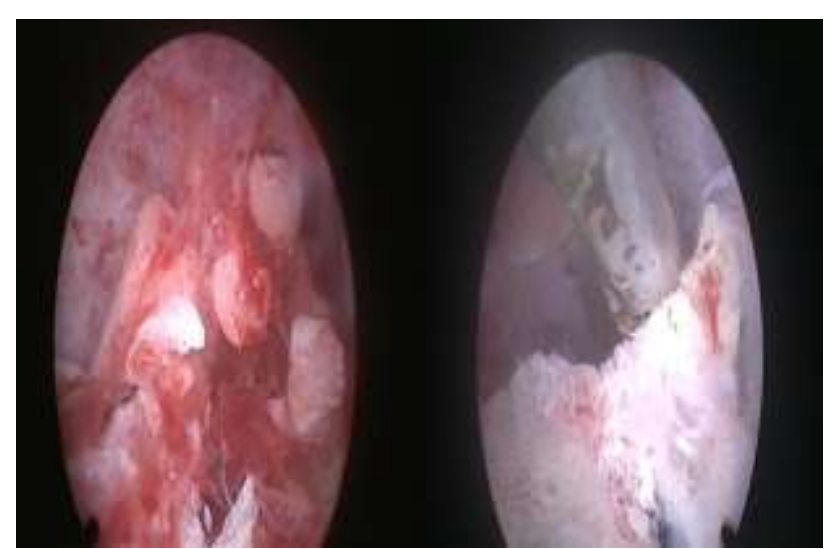

Figure 2: Hysteroscopic appearance of bony fragments in the uterus.

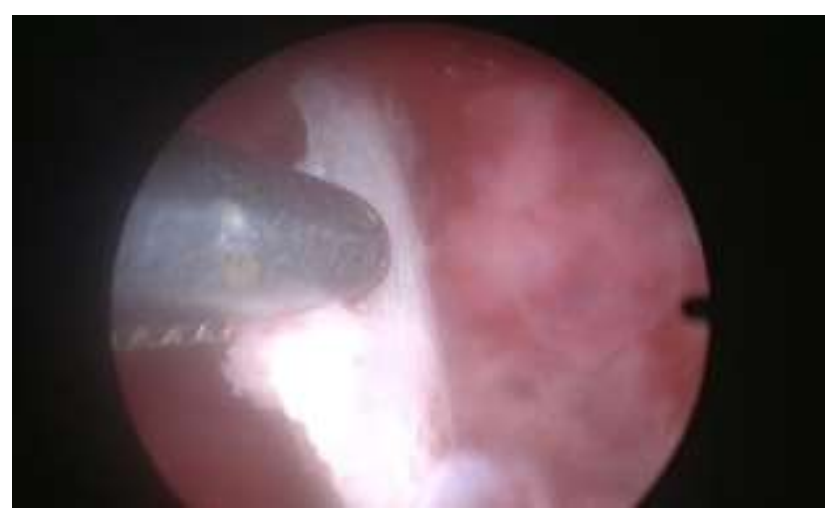

Figure 3: Bony fragments being removed using $5 \mathrm{Fr}$ hysteroscopic grasper.

Patient conceived spontaneously 3 months after the procedure. Her antenatal period was uneventful. She underwent a normal vaginal delivery of a healthy male child weighing $3.1 \mathrm{~kg}$ at term.

\section{DISCUSSION}

Osseous metaplasia of endometrium, also named variously as endometrial ossification, ectopic intrauterine bone, heterotopic intrauterine bone etc. is an uncommon clinical entity with $<100$ cases being reported in the literature. ${ }^{9}$ It is an endogenous non neoplastic pathological disorder which may also involve the cervix, ovary and the vagina. ${ }^{4,10-12}$

Majority of the affected patients are in the reproductive age group, though a rare case of post-menopausal osseous metaplasia of endometrium has been reported by Shimizu et al. ${ }^{13}$ Almost all the patients have a history of previous first trimester abortions, spontaneous or induced. ${ }^{2-5}$ The time interval between previous abortion and diagnosis of osseous metaplasia may vary from 8 weeks to 14 years, however, cases up to 37 years after abortion have been reported in the literature. ${ }^{5,13}$ 
Patients may present with an array of symtoms viz. dysmenorrhoea, pelvic pain, menstrual irregularities, vaginal discharge, secondary infertility etc. ${ }^{5,7}$ Patients may also remain asymptomatic with osseous metaplasia being only an incidental finding. ${ }^{4}$ Our case had presented with hypomenorrhoea and secondary infertility. The postulated mechanism for infertility is that the bony tissue in the uterus acts like an intrauterine contraceptive device, causing increase in the levels of prostaglandins, thus preventing blastocyst implantation. ${ }^{14}$

Various hypotheses have been proposed for defining the possible etiology of this rare disorder. Metaplastic transformation of uterine fibroblasts into bone forming osteoblasts is the most widely accepted theory. ${ }^{4,13}$ Other theories are- prolonged estrogenic endometrial stimulation; chronic endometritis, pyometra causing metaplasia of uterine fibroblasts; dystrophic calcification in retained products of conception and post abortive endometritis etc. ${ }^{4-6}$ Tubercular endometritis can also lead to endometrial ossification and should be ruled out, especially in Indian population. ${ }^{15}$ In our patient, endometrial TB-PCR turned out to be negative.

Association of osseous metaplasia of endometrium with hypercalcemia or conditions causing hypercalcemia is rare and most cases have normal levels of serum calcium, as in our case. Adamson and Sommers have reported a case of endometrial ossification in a patient taking high dose of calcium and vitamin D for prolonged period. ${ }^{1}$

Recent genetic studies on the origin of endometrial bone have shown differing results. Cayuela et al and Parente et al confirmed that the bony tissue was of maternal origin, thus representing true osseous metaplasia. ${ }^{9,16}$ On the other hand, Tulandi et al found the bony tissue to be of fetal origin. $^{17}$

Differential diagnosis of this disorder include endometrial tuberculosis, IUCD, malignant mixed mullerian tumour of endometrium and retained fetal bones after abortion. ${ }^{18}$ Ultrasonography is a useful modality to suspect and diagnose the presence of bony tissue in the uterus. It usually shows characteristic hyperechoic appearance of bony tissue, as was seen in our case.

Hysteroscopy is now considered the gold standard for definitive diagnosis and treatment of osseous metaplasia of endometrium. ${ }^{5-7}$ Other treatment modalities like dilatation \& curettage and hysterectomy are rarely, if at all, required. In difficult or extensive cases, hysteroscopic resection of bony tissue can also be performed under ultrasound or laparoscopy guidance to prevent perforation of uterus. ${ }^{18}$ Successful hysteroscopic removal of bony fragments restores fertility and literature has shown good conception rates after treatment. ${ }^{7,8}$ In our case too, successful hysteroscopic management was followed by spontaneous conception.

\section{CONCLUSIONS}

Osseous metaplasia of endometrium, though rare, is an important cause of secondary infertility which must be kept in mind. High index of suspicion will help in accurate diagnosis and management of this rare disorder. With the advent and development of hysteroscopy as a diagnostic and treatment modality, fertility can be restored completely with good pregnancy outcomes.

\section{Funding: No funding sources \\ Conflict of interest: None declared \\ Ethical approval: Not required}

\section{REFERENCES}

1. Adamson NE, Sommers SC. Endometrial ossification: report of two cases. Am J Obstet Gynecol. 1954;67:187-90.

2. Onderoglu LS, Yarali H, Gultekin M, Katlan D. Endometrial osseous metaplasia: an evolving cause of secondary infertility. Fertil Steril. 2008;90(5):2013.e9-11.

3. Hsu C. Endometrial ossification. $\mathrm{Br} \mathrm{J}$ Obstet Gynaecol. 1975;82:836-9.

4. Bhatia NN, Hoshiko MG. Uterine osseous metaplasia. Obstet Gynecol. 1982;60:256-9.

5. Bahçeci M, Demirel LC. Osseous metaplasia of the endometrium: a rare cause of infertility and its hysteroscopic management. Hum Reprod. 1996;11:2537-9.

6. Umashankar T, Patted S, Handigund R. Endometrial osseous metaplasia: Clinicopathological study of a case and literature review. J Hum Reprod Sci. 2010;3:102-4.

7. Lainas T, Zorzovilis I, Petsas G, Alexopoulou E, Lainas G, Loakimidis T. Osseous metaplasia: Case report and review. Fertil Steril. 2004;82(5):1433-5.

8. Kouakou F, Loué V, Kouamé A, Adjoby R,Koui S, Koimé $\mathrm{H}$ et al. Endometrial osseous metaplasia and infertility: a case report. Clin Exp Obstet Gynecol. 2012;39(4):559-61.

9. Cayuela E, Perez-Medina T, Vilanova J, Alejo M, Cañadas P. True osseous metaplasia of the endometrium: the bone is not from a fetus. Fertil Steril. 2009;91:1293.e1-4.

10. Bedaiwy MA, Goldberg JM, Biscotti CV. Recurrent osseous metaplasia of the cervix after loop electrosurgical excision. Obstet Gynecol. 2001;98:968-70.

11. Campo S, Campo V, Zannoni GF, Gambadauro P. Simultaneous ovarian and endometrial osseous metaplasia: A case report. J Reprod Med. 2007;52:241-2.

12. Landim FM, Tavares JM, de Melo Braga DN, da Silva JE, Jr, Bastos Filho JB, Feitosa RG. Vaginal osseous metaplasia. Arch Gynecol Obstet. 2009;279:381-4. 
13. Shimizu M, Nakayama M. Endometrial ossification in a postmenopausal woman. J Clin Pathol. 1997;50:171-2.

14. Marcus SJ, Bhattacharya J, Williams G, Brinsden P, Hamou J. Endometrial ossification a cause of secondary infertility. Am J Obstet Gynecol. 1994;170:1381-3.

15. Shroff CP, Kudterkar NG, Badhwar VR. Endometrial ossification-- report of three cases with literature review. Indian J Pathol Microbiol. 1985;28:71-4.

16. Parente RC, Patriarca MT, de Moura Neto RS, de Oliveira MA, Lasmar RB, de Holanda Mendes P, et al. Genetic analysis of the cause of endometrial osseous metaplasia. Obstet Gynecol. 2009;114:11038.
17. Tulandi T, Al-Sunaidi M, Arseneau J et al. Calcified tissue of fetal origin in utero. Fertil Steril. 2008;89(1):217-8.

18. Madaan M, Suman S, Sharma R, Kapoor N, Garg P, Raj SS. Osseous metaplasia of the endometrium and successful hysteroscopic resection: report of two cases and a review of the literature. Asian $\mathrm{J}$ Endosc Surg. 2015;8(1):63-6.

Cite this article as: Shah NH, Kale KG, Shah VN. Osseous metaplasia of endometrium: A rare cause of secondary infertility. Int J Reprod Contracept Obstet Gynecol 2016;5:532-5. 